DOI: https://doi.org/10.11144/Javeriana.upsy18-2.erbt

\title{
Examining the Relation between Purpose in Life and Self-Reported Health in Community and Inpatient Populations*
}

\section{Relación entre propósito de la vida y salud autoinformada en población normal y psiquiátrica}

\author{
Alba Escura \\ Universidad de Zaragoza, España \\ Sonsoles Valdivia-Salas ${ }^{\text {a }}$ \\ Universidad de Zaragoza, España \\ ORCID: http://orcid.org/0000-0002-0242-5972 \\ José Martín-Albo \\ Universidad de Zaragoza, España \\ ORCID: http://orcid.org/0000-0003-4417-5470 \\ Pablo J. L. Zaldívar \\ Universidad de Zaragoza, España \\ ORCID: http://orcid.org/0000-0003-2659-6220 \\ Ginesa López-Crespo \\ Universidad de Zaragoza, España \\ ORCID: http://orcid.org/0000-0002-9928-7317
}

a Correspondence author. Email: sonsoval@unizar.es

How to cite: Escura, A., Valdivia-Salas, S., MartínAlbo, J., Zaldívar, P. J. L., \& López-Crespo, G. (2019). Examining the relation between purpose in life and self-reported health in community and inpatient populations. Universitas Psychologica, 18(2), 1-11. https://doi.org/10.11144/Javeriana.upsy18-2.erbt

\begin{abstract}
The goal of the present study was to examine whether the relation commonly found between purpose in life and well-being occurs regardless of the population being assessed (community vs. inpatient) when the presence of somatic symptoms is used as a proxy for well-being. A total of 145 adults participated in the study (psychiatric patients, $N=28$; healthy community adults, $N=117$ ). Statistical analyses were first conducted to control for the effects of the observed differences in age and gender between samples. Results showed a significant relation between purpose in life and perceived health even after controlling for population. In both community and inpatient populations, purpose in life correlated with fewer somatic concerns. We discuss the benefits of incorporating a sense of directedness with prevention and treatment purposes.

Keywords

Purpose in life; self-reported health; mentally ill; healthy adults; well-being.
\end{abstract}

\section{RESUMEN}

El objetivo del presente estudio fue examinar si la relación comúnmente encontrada entre propósito de la vida y bienestar ocurre con independiencia de la población bajo estudio (normal vs psiquiátrica) y cuando se utiliza la presencia de síntomas somáticos como indicador de bienestar. Un total de 145 adultos participaron en el estudio (población psiquiátrica, $N=28$; población normal, $N=117$ ). En primer lugar, se realizaron análisis estadísticos para controlar los efectos de las diferencias observadas entre grupos en la edad y género de los participantes. En 
segundo lugar, los análisis realizados sobre la relación entre las dos variables objeto de estudio mostraron una relación significativa entre propósito de la vida y salud percibida después de controlar por población estudiada. Esto es, en ambas poblaciones, un propósito de la vida mejor definido correlacionó con menor frecuencia de síntomas somáticos. Se discuten los beneficios de incorporar un sentido de dirección en la vida a cualquier intervención psicológica que tenga fines preventivos y curativos.

Palabras clave

propósito de la vida; salud autoinformada; enfermos psiquiátricos; adultos normales; bienestar.

If one were to choose the subject matter of Psychology, this would most probably be wellbeing. Wellbeing has been regarded as the degree to which an individual judges the quality of his life in a favorable way (Veenhoven, 1984); the combination of frequent positive affect and seldom negative affect (Diener \& Larsen, 1993); or the combination of self-acceptance, personal growth, purpose in life, positive relations with others, environmental mastery, and autonomy (Ryff \& Keyes, 1995).

In theoretical terms, wellbeing has been regarded as the direct consequence of a life devoted to a purpose (Kashdan \& McKnight, 2013). Within this framework, the most obvious dimension of wellbeing is a sense of meaning in life, which arises as the person makes progress towards her purpose in life (Kashdan \& McKnight, 2013). In the present review, however, we use the concepts of purpose in life and meaning in life indistinctively. V. Frankl first described meaning in life after surviving several Nazi death camps during World War II. There he learned that searching for purpose in life is common to all human beings and never ends in that it entails taking responsibility for everyday actions (Frankl, 1959). Assuming that purpose in life imposes some direction to daily action, Frankl stated that mental wellbeing could be found in the tension between what the person is and has accomplished so far, and what the person longs. If for some reason, purpose in life is blocked, psychological problems will arise.

The construct purpose in life as regarded by Frankl (1959) is measured with the Purpose in
Life Test (PIL; Crumbaugh \& Maholick, 1964), which "measures the degree to which individuals experience life as meaningful and develop a sense of purposeful direction" (Lundman et al., 2010, p. 253). By using this scale, early research revealed that older adults tend to present a better-defined purpose in life than their younger counterparts. As for gender, women tended to show more will to find meaning than men, but there was not an actual difference in their purpose. More recently, however, the relationship between purpose in life and life satisfaction and health has proven independent of age and gender (Boyle, Barnes, Buchman, \& Bennet, 2009; for related evidence, see Hill, Turiano, Spiro, \& Mroczek, 2015; and Wiesmann \& Hannich, 2013).

In healthy populations, purpose in life has been widely shown to correlate positively with self-esteem, affect balance, the ability to cope, the will to live, and lower risk of mortality; and negatively with drug abuse, depression, neuroticism, anxiety, loneliness/boredom, and the risk of all-cause mortality and cardiovascular events (e.g., Boyle et al., 2009; Cohen, Bavishy, \& Rozanski, 2016; García-Alandete, 2015; GarcíaAlandete, Rosa, \& Sellés, 2013; Hill, Edmonds, \& Hampson, 2017; Hill \& Turiano, 2014; Hill, Turiano, Mroczek, \& Burrow, 2016; Hooker \& Masters, 2016; Irving, Davis, \& Collier, 2017; Kashdan \& McKnight, 2013; Kim, Hershner, \& Strecher, 2015; Kim, Kawachi, Chen, \& Kubzansky, 2017; Kim, Strecher, \& Ryff, 2014; Kim, Sun, Park, Kubzansky, \& Peterson, 2013; Windsor, Curtis, \& Luszcz, 2015). High PIL scores have also proven to be a good predictor of higher self-esteem, internal locus of control and reduced distress among cancer patients and other medical and psychiatric conditions (e.g., Marco, García-Alandete, Pérez, \& Botella, 2014; Sherman \& Simonton, 2012);

As for the mentally ill, it is generally assumed that people with a mental health condition suffer from a loss of meaning and purpose in life which lead to less involvement in daily activities that might, in turn, help create meaning in life (Ehrlich-Ben et al., 2013; García-Alandete, Marco, \& Pérez, 2017). However, the empirical research on purpose in life and its relation to 
psychological and physical well-being in people with a mental health condition is minimal. In a sample of 49 patients of a tertiary care psychiatric hospital, 40 of them inpatients, Heisel and Flett (2004) showed that a well-defined purpose in life protected against suicidal ideation. To explore the relationship among various personality, psychiatric, and subjective variables, Strack and Schulenberg (2009) showed that the presence of meaning in life was associated with the variable empowerment and the level of psychiatric symptoms in an inpatient sample of 94 individuals with serious mental illness. Lastly, García-Alandete et al. (2017) demonstrated the fit of Frankl's model of purpose in a sample of Spanish mental health patients.

Considering that PIL is the most influential measure of purpose, serving as the foundation for subsequent instruments (Damon, Menon, \& Bronk, 2003), our main goal was to examine whether the protective role of purpose in life on mental patients' self-reported health is also found when the former is measured with the PIL scale. Indeed, this is the first study that directly compares the relation between PIL, as measured with the PIL test, and wellbeing in both community and inpatient populations aiming at analyzing whether this relation is somehow influenced by the type of population assessed. Additionally, we aimed to explore the scope of the benefits of purpose in life; in other words, whether beyond affective (e.g., selfesteem) and instrumental (e.g., internal locus of control) variables, purpose in life correlates with a general sense of health as measured with the General Health Questionnaire (GHQ), in both community individuals and mental inmates. Specifically, we tested the following aims: (1) whether the type of population (inpatient vs. community) influences PIL and GHQ scores beyond other demographic characteristics, and (2) whether the relation between PIL and GHQ exists regardless of the population (inpatient vs. community) being tested.

\section{Method}

\section{Participants}

A total of 145 adults participated in this study. The inpatient sample included 28 chronic institutionalized patients $(82.14 \%$ male) whose age ranged between 31 and 74 years $(M=$ 54.0; $S D=10.96)$. Schizophrenia was the most frequent diagnosis (57.14\% of the sample). Inpatients were recruited who presented fair cognitive and executive functioning (total score of $27 / 30$ or higher in the Spanish validation of the Mini-Mental State Examination, by Lobo, Ezquerra, G'mez-Burgada, Sala \& Seve-Días, 1979) and emotional stability, according to their medical record and the staff criteria. The community sample included 117 adults $(39.32 \%$ male) whose age ranged between 17 and 67 years old $(M=32.17 ; S D=14.04)$ and who met the inclusion criteria mentioned above. The community sample was recruited through online advertisement, and their data were collected through an online survey. In both groups, sampling was carried out according to sample accessibility, and participation was voluntary.

The difference in age and gender between groups resulted in further statistical computations to control for their effects on the target relation.

\section{Design, Procedure and Measures}

We employed a correlational and transversal design (Ato García \& Vallejo Seco, 2011) to evaluate the relation between PIL and a general sense of health in naturally occurring groups of populations, i.e., community and inpatient adults.

The Human Research Ethics Committee at the university and the hospital reviewed and approved the study. At the hospital, the staff recruited the participants and assisted during questionnaires administration by reading the items and writing the answer when necessary (9.7\% of cases). All participants were asked to complete the task in a quiet environment. 
Completion time was $15 \mathrm{~min}$ on average. Participants completed:

Purpose in Life Test (PIL, Crumbaugh \& Maholick, 1964). PIL measures purpose in life and/or existential vacuum, following Frankl's definition of the concept. We used the Spanish validation (Noblejas de la Flor, 2000), including 20 items rated on a 7-point Likert format, from 1 (indicating existential vacuum) to 7 (indicating full purpose in life). The Spanish validation of the PIL is a reliable instrument, with a Cronbach's alpha of 0.879 (Noblejas de la Flor, 2000). The total score in the PIL ranges between 20 and 140, with higher scores indicating the presence of goals and purpose in life. We note that for the ease of responding in the inpatient sample, we reduced the Likert scale to 5 points; therefore, the total scores in our study ranged between 20 and 100.

General Health Questionnaire (GHQ-28, Goldberg \& Hillier, 1979). GHQ-28 measures self-reported general health and is frequently used as an indicator of psychological wellbeing (Goldberg \& Hillier, 1979). We used the Spanish validation of the GHQ-28 (Lobo, PérezEchevarría, \& Artal, 1986), which shows high test-retest reliability $(r=0.90)$, sensitivity of $84.6 \%$ and specificity of $82 \%$ (García-Moratalla, 2008; Lobo et al., 1986). The GHQ-28 includes 28 items grouped in four factors, each of them including 7 items with four possible answers, ranging from 0 (Not at all) to 3 (much more than usual). The four factors are: 1 ) somatic symptoms or hypochondria; 2) anxiety and insomnia; 3) social dysfunction; and 4) severe depression the total score range between 0 and 84, with high scores indicating poor self-reported health. In our study, the GHQ-28 was used as a general indicator of self-reported health, so the total score was entered in the analyses (Sterling, 2011).

\section{Data Analysis}

SPSS version 16.0 was used for coding data, estimating models and performing univariate statistical computations. Univariate (means, standard deviation, skewness, and kurtosis) and bivariate statistics (correlations) were first computed. After that, univariate statistical analyses were conducted to test for differences in gender and age between the inpatient and the community sample. A two-tailed parametric t-test for independent samples, not assuming equal variances, was used to compare mean ages. A two-tailed Pearson chi-squared test and the Fisher's exact test (given the small sample size) were conducted to compare gender.

Multivariate inferential analyses were conducted using structural equation modeling (SEM) to test the possible influence of population (inpatient vs. community) on the relation between PIL and GHQ. We employed SEM because, as compared to less complex and robust analyses, it allows controlling for measurement errors due to the observed variability between samples. SEM was performed through Mplus 6.01 software (Muthén \& Muthén, 1998; 2010) using robust maximum likelihood. To evaluate the fit of the models, the following goodness-of-fit indices were reported: Chi-square test for model fit $\left(\chi^{2}\right)$, Root Mean Square Error of Approximation (RMSEA), Comparative Fit Index (CFI), TuckerLewis Index (TLI) and Standardized Root Mean Square Residual (SRMR). Across analyses, the alpha level was set at 0.05, and when the probability of estimators was lower than 0.01 , statistical reliability of 0.01 was informed. Two nested models were compared. Loglikelihood Chi-Square Difference Test was performed to obtain the significance of the comparison of the models.

For statistical analyses comparing the potential difference in magnitude between regression coefficients from independent samples (inpatient vs. community), we used the Fisher r-to-z transformation.

\section{Results}

\section{Descriptive statistics}

Table 1 shows the descriptive statistics (bivariate correlations, means and standard deviations) and 
reliability of PIL and GHQ scores. As expected, PIL average score was higher in the community than in the inpatient group, whereas GHQ average score was higher in the inpatient than in the community group. The correlation between PIL and GHQ was negative and significant ( $\mathrm{p}$ $<0.05$ ) in both groups, being of slightly higher magnitude in the inpatient group.

Statistical analyses revealed that inpatient participants were significantly older than community participants $(54.0$ and 32.17 years old respectively), $t(50.58)=8.93, p<0.01$. As well, most community participants were female $(60.7 \%)$, while most inpatients were male $(82.1 \%)$. Analyses showed that there was a significant relationship between gender and sample, $\chi^{2}(1)=16.614, p<0.01$ for Pearson chisquared test and $\mathrm{p}<.01$ for Fisher's exact test.

Table 1

Correlations, descriptive statistics and reliability for observable variables in community and inpatient samples. PIL $=$ Purpose in Life Test. GHQ = General Health Questionnaire

\begin{tabular}{|c|c|c|c|c|}
\hline \multirow{2}{*}{ Coeficient } & \multicolumn{2}{|c|}{ Community } & \multicolumn{2}{|c|}{ Inpatient } \\
\hline & PIL & GHQ & PIL & GHQ \\
\hline$r_{\mathrm{xy}}$ & & $-0.55^{*}$ & & $-0.67 *$ \\
\hline Mean & 76.86 & 45.32 & 69.43 & 54.39 \\
\hline SD & 8.65 & 8.80 & 14.82 & 11.10 \\
\hline Skew & -0.54 & 0.84 & -0.32 & 1.03 \\
\hline Kurtosis & 1.00 & 0.49 & -0.71 & 1.67 \\
\hline Alpha & 0.81 & 0.89 & 0.90 & 0.88 \\
\hline
\end{tabular}

\section{Structural Equation Models}

The first model included age, sex and type of population as covariates influencing PIL and GHQ scores. The model was just-identified (the number of free parameters exactly equals the number of known values, with zero degrees of freedom), $X^{2}=0, d f=0, p<0.01$, RMSEA $=0, \mathrm{CFI}=1.00, \mathrm{TLI}=1.00, \mathrm{SRMR}=0 . \mathrm{As}$ Table 2 shows, out of the three covariables, only population resulted significantly related with GHQ $(\beta=0.319, p<0.05)$, and expectedly, PIL and GHQ were negatively related $(\beta=-0.56, p$ $<0.05)$. This model explained $42 \%$ of the GHQ variance $(p<0.01)$, and $10 \%$ of the PIL variance $(p>0.05)$.

\section{Table 2}

Path analysis with demographic variables. SE $=$ Standard Error

\begin{tabular}{|c|c|c|c|c|}
\hline Variable & $\begin{array}{c}\text { Estimate } \\
\text { (standardized) }\end{array}$ & $\begin{array}{c}\text { SE } \\
\text { (standardized) }\end{array}$ & $p$ & $R^{2}$ \\
\hline \multicolumn{5}{|l|}{ GHQ on } \\
\hline Age & $0(0.03)$ & $0.00(0.08)$ & 0.71 & \multirow{4}{*}{0.42} \\
\hline Gender & $0.02(0.03)$ & $0.06(0.08)$ & 0.72 & \\
\hline Population & $0.18(0.19)$ & $0.07(0.07)$ & 0.01 & \\
\hline PIL & $-0.38(-0.56)$ & $0.05(0.05)$ & 0.01 & \\
\hline \multicolumn{5}{|l|}{ PIL on } \\
\hline Age & $-0.01(-0.16)$ & $0(0.10)$ & 0.11 & \multirow[t]{3}{*}{0.10} \\
\hline Gender & $-0.10(-0.09)$ & $0.09(0.09)$ & 0.29 & \\
\hline Population & $-0.30(-0.22)$ & $0.17(0.13)$ & 0.08 & \\
\hline
\end{tabular}

To further the analysis of the positive and significant contribution of population on GHQ scores, we tested two nested models in which only the variable population was included as a predictor variable (MacKinnon, 2008): model a was unconstrained; and, in model $\mathrm{b}$, the path of population on PIL and GHQ was constrained to zero. The results are shown in Table 3.

Table 3

Path analysis: Nested models. SE $=$ Standard Error

\begin{tabular}{rrrr}
\hline \multicolumn{1}{c}{ Model } & $\begin{array}{c}\text { Estimate } \\
\text { (standardized) }\end{array}$ & $\begin{array}{c}\text { SE } \\
\text { (standardized) }\end{array}$ & $p$ \\
\hline Model $a$ (Unconstrained) & & & \\
GHQ on Population & $0.18(0.20)$ & $0.06(0.06)$ & 0.01 \\
GHQ on PIL & $-0.38(-0.56)$ & $0.05(0.05)$ & 0.01 \\
PIL on Population & $-0.37(-0.28)$ & $0.14(0.10)$ & 0.01 \\
& & & \\
Model $b$ (constrained Population $=0$ ) & & & \\
GHQ on Population & $0(0)$ & $0(0)$ & \\
GHQ on PIL & $-0.42(-0.62)$ & $0.05(0.05)$ & 0.01 \\
PIL on Population & $0(0)$ & $0(0)$ & \\
\hline
\end{tabular}

The analyses yielded model $a$ as a justidentified model $\left(X^{2}=0, d f=0, p<0.01\right.$, $\mathrm{RMSEA}=0, \mathrm{CFI}=1.00$, TLI $=1.00$, SRMR $=0)$. The explained variance was of $42 \%$ for GHQ $(p<0.01)$ and $.08 \%$ for PIL $(p>0.05)$. Model $\mathrm{b}$ did not show good fit $\left(X^{2}=16.17 \mathrm{df}\right.$ $=2, p>0.05, \mathrm{RMSEA}=0.22, \mathrm{CFI}=0.80$, TLI $=0.70$, SRMR $=0.15)$. The model explained $38 \%$ of GHQ variance $(p<0.01)$. Further analyses revealed that the confidence intervals of model a and model b overlapped, hence the path difference between models was not significant. A Loglikelihood Chi-Square Difference Test (see Table 4) revealed that model $a$ and model $b$ were significantly different, indicating that PIL 
and GHQ scores were influenced by type of population.

\section{Table 4}

Loglikelihood Chi-Square Difference Test

\begin{tabular}{lrr}
\hline \multicolumn{1}{c}{ Indicator } & Model a & Model $\boldsymbol{b}$ \\
\hline Loglikelihood & -122.435 & -132.706 \\
Scaling correction factor & 1.258 & 1.253 \\
$d f$ & 7 & 5 \\
\hline$\chi^{2}$ difference Test & 16.17 & \\
Difference test scaling correction & 1.271 & \\
$p$ & 1.001 \\
\hline
\end{tabular}

\section{Different between regression coefficients}

In order to determine whether the relation between PIL and GHQ was different for the inpatient and the community populations, we conducted regression analyses on each sample and a Fisher $r-$ to $-z$ transformation. As Table 5 shows, the regression coefficients were negative and significant in both samples $(p<0.01)$. Fisher transformation showed that the confidence intervals of the difference contained zero, thus rejecting the hypothesis that the path was different on each population. In other words, the relation between PIL and GHQ was the same in both community and inpatient populations.

Table 5

Fisher $r$-to-z transformation

\begin{tabular}{|c|c|c|c|c|c|c|c|c|c|c|}
\hline \multirow{2}{*}{ Sample (N) } & \multirow{2}{*}{ Path } & \multirow{2}{*}{$\mathbf{Z}_{\text {fisher }}$} & \multirow{2}{*}{ dif } & \multirow{2}{*}{$\mathbf{Z}_{\text {dif }}$} & \multirow{2}{*}{ SEz dif } & \multicolumn{2}{|c|}{$\mathbf{Z}_{\text {dif } 95 \%}$ IC } & \multicolumn{3}{|c|}{$\mathbf{r}_{\text {dirf5\% }}$ IC } \\
\hline & & & & & & Low & High & $r_{\text {dif }}$ & Low & High \\
\hline Community (117) & $-0.40^{*}$ & -0.42 & & & & & & & & \\
\hline Inpatient (28) & $-0.36^{*}$ & -0.37 & -0.05 & -0.22 & 0.22 & -0.48 & 0.38 & -0.05 & -0.45 & 0.37 \\
\hline
\end{tabular}

\section{Discussion}

Community individuals in our study reported a better-defined purpose in life and better self-reported health than institutionalized individuals. Most importantly, there was a significant negative relation between PIL scores and GHQ scores in both groups. This means that independently of the population being assessed, defining the purpose or direction in one's life correlates with the better self-reported state of health. Furthermore, statistical analyses revealed that the significant differences found in gender and age between groups did not influence the relationship between purpose and self-reported health.

As the path analysis showed, our findings are consistent with the evidence that psychiatric patients usually lack a sense of directedness in their lives (e.g., García-Alandete et al., 2017; Heisel \& Flett, 2004). Same as in the original validation of the test, in our study, PIL scores distinguished significantly between psychiatric patient and nonpatient populations, with hospitalized patients scoring the lowest (Crumbaugh \& Maholick, 1964; Damon et al., 2003). A short form of the PIL test has been validated with a healthy undergraduate population (Schulenberg, Schnetzer, \& Buchanan, 2011). Future research may investigate whether it is also useful and predictive of psychological distress and somatic concerns among psychiatric inmate populations.

As expected, GHQ scores in the inpatient sample in our study were significantly larger than those of the community sample, meaning that institutionalized patients reported poor health. This supports the view that the GHQ scores serve to determine the probability of a person being a psychiatric case (Weich, Twigg, Holt, Lewis, \& Jones, 2003). Also, it serves as additional evidence that people reporting little purpose or direction in life report not only numerous negative life events, hassles and grief (e.g., Hill et al., 2016; Marco et al., 2014), but also the general sense of a poor health, indicated by symptoms such as bad sleep quality, and pain and tightness in their heads (see also, Hooker \& Masters, 2016; Kim et al., 2015; Kim et al., 2017; Kim et al., 2014; Kim et al., 2013). Although the cross-sectional nature of our study hinders conclusions about causality, we can assert that our findings broaden the scope of the negative influence of the lack of purpose in one's life, from psychological and spiritual issues to somatic concerns. Longitudinal, as well as experimental studies, will be critical in future studies to examine temporal relationships between purpose 
in life and self-reported general health in both community and inpatient populations.

Early research suggested that giving mental health patients and elderly nursing home residents the responsibility of their daily choices (e.g., by offering plants to take care of, or allowing them to choose what to do in their leisure time) results in more involvement in different kinds of activities, more sociability and self-initiation, even lower mortality rates (for seminal evidence, see Langer \& Rodin, 1976; Rodin \& Langer, 1977; for related evidence, see Ayllon \& Azrin, 1968). These findings have been confirmed in later studies, pointing to the sense directedness and intentionality as a resilience factor protecting against the harmful consequences of being diagnosed with a psychiatric condition, such as stigma (e.g., Ehrlich-Ben et al., 2013; Kashdan \& McKnight, 2013; Schaefer et al., 2013).

Health promotion and education interventions within mainstream health psychology have largely relied on informational resources as the foundation of behavior change. Alternatively, some authors have raised their voice to claim that health behaviors are intimately related to issues of meaning, value and identity (e.g., Hill et al., 2017; Kim et al., 2014). Recent work on acceptance within Acceptance and Commitment Therapy (ACT; Hayes, Strohsal, \& Wilson, 1999; 2011) becomes especially relevant in this regard. ACTbased interventions focus on assisting people to develop, clarify, and pursue their purpose by promoting actions that are deliberate and consistent with such purpose (e.g., Wilson \& Murrell, 2004), and thus turning purpose in life into a core therapeutic element. Within ACT, the purpose has been regarded as self-organizing in that "it provides a framework for systematic behavior pattern in everyday life" (Kashdan \& McKnight, 2013, p. 304). As well, a purpose -or valued direction using ACT terminologyis unachievable by definition, but it facilitates the decision-making process when confronted with competing behavioral options (such as in approach-avoidance conflicts), or when a specific goal turns out unattainable for whatever reason: in the first case by turning the purpose-consistent option into more salient (e.g., Páez-Blarrina et al., 2008; Valdivia-Salas, Blanchard, Lombas, \& Wulfert, 2014; Valdivia-Salas, Dougher, \& Luciano, 2013); in the second case by facilitating the emergence of new and more attainable purpose-consistent goals (Kashdan \& McKnight, 2013).

The diagnosis of a mental condition might be overwhelming to the extent that it implied the failure to attain specific goals and thus the disengagement from them. In some cases, this very fact may lead to the emergence of new attainable goals, some of which could be existential in nature, resulting in a more positive interpretation of life and engagement in meaningful activities (Ehrlich-Ben et al., 2013). When this does not happen, mental health patients may benefit from interventions that target the finding of purpose in life, the definition of purpose-consistent goals and behaviors, and the pursuit of such goals. This is because setting a purpose may turn daily actions into steps in or against such direction, hence facilitating the act of choosing and the reappraisal of the negative events that come along such as negative affect, sense of uselessness, or fear (e.g., Luciano et al., 2010).

The present study has some limitations which need to be addressed in future studies if we were to grasp the whole nature and scope of the relationship between purpose and self-reported health. First of all, the fact that our samples were unbalanced in terms of gender and age forced us to conduct complex data analyses to make sure these differences did not influence the relation tested. Also, the reduced number of inpatient participants did not allow us controlling for several possible covariates in the relationship between purpose and self-reported health such as type of psychiatric condition, past or current pharmacological and psychological treatment, or duration of hospitalization. Likewise, the examination of the possible role played by covariates such as personality characteristics (e.g., optimism, neuroticism) and other variables such as depression, negative affect, or emotion regulation in the community population may help identify the specific conditions under which 
purpose in life may turn into a protective factor against somatic concerns. Lastly, as mentioned previously, only longitudinal studies will clarify the directionality of the relation between the two variables at hand.

All in all, these findings add to empirical demonstration that the presence of a welldefined purpose in life, as measured with the PIL test, is related to fewer somatic concerns and a general sense of better self-reported health, as measured with the GHQ, in both a community sample and a hospitalized psychiatric sample. These preliminary findings set the stage for further examination of the nature and scope of this relationship to facilitate the design of evidence-based health promotion interventions incorporating core issues such as the valuesbased reappraisal of the diagnosis of a psychiatric condition.

\section{References}

Ato García, M., \& Vallejo Seco, G. (2011). Diseños de investigación en Psicología [Research designs in Psychology]. Madrid: Pirámide.

Ayllon, T., \& Azrin, N. (1968). The token economy: A motivational system for therapy and rehabilitation. New York: Appleton Century Crofts.

Boyle, P. A., Barnes, L. L., Buchman, A. S., \& Bennet, D.A. (2009). Purpose in life is associated with mortality among community-dwelling older persons. Psychosomatic Medicine, 71(5), 574-579. https://doi.org/10.1097/PSY.0b01 $3 \mathrm{e} 3181 \mathrm{a} 5 \mathrm{a} 7 \mathrm{c0}$

Cohen, R., Bavishi, C., \& Rozanski, A. (2016). Purpose in life and its relationship to allcause mortality and cardiovascular events: A meta-analysis. Psychosomatic Medicine, 78(2), 122-133. https://doi.org/10.1097/PS Y.0000000000000274

Crumbaugh, J. C., \& Maholick, L. T. (1964). An experimental study in existentialism: The psychometric approach to Frankl's concept of noogenic neurosis. Journal of
Clinical Psychology, 20(2), 200-207. https:// doi.org/10.1002/1097-4679(196404)20:2< 200::AID-JCLP2270200203>3.0.CO;2-U

Damon, W., Menon, J., \& Bronk, K. C. (2003). The development of purpose during adolescence. Applied Developmental Science, 7(3), 119-128. https://doi.org/10.1207/S15 32480XADS0703_2

Diener, E., \& Larsen, R. J. (1993). The subjective experience of emotional well-being. In $\mathrm{M}$. Lewis \& J. M. Haviland (Eds.), Handbook of emotions (pp. 405-415). New York: Guilford Press.

Ehrlich-Ben, O., Hasson-Ohayon, I., Feingold, D., Vahab, K., Amiaz, R., Weiser, M., \& Lysaker, P. H. (2013). Meaning in life, insight and self-stigma among people with severe mental illness. Comprehensive Psychiatry, 54(2), 195-200. https://doi.org/1 0.1016/j.comppsych.2012.07.011

Frankl, V. E. (1959). Man's search for meaning. Boston: Beacon Press.

García-Alandete, J. (2015). Does meaning in life predict psychological well-being? An analysis using a Spanish versions of the Purpose-In-Life Test and the Ryff's Scales. The European Journal of Counselling Psychology, 3(2), 1-10. https://doi.org/10.59 64/ejcop.v3i2.27

García-Alandete, J., Marco, J. H., \& Pérez, S. (2017). Purpose-in-Life Test: Comparison of the main models in patients with mental disorders. The Spanish Journal of Psychology. https://doi.org/10.1017/sjp.2017.28

García-Alandete, J., Rosa, E., \& Sellés, P. (2013). Estructura factorial y consistencia interna de una versión española del PurposeIn-Life Test [Factorial structure and internal consistency of a Spanish version of the Purpose-In-Life Test]. Universitas Psychologica, 12, 517-530. https://doi.org/10 .11144/Javeriana.UPSY12-2.efci

García-Moratalla, B. (2008). Análisis prospectivo de las consultas sin diagnóstico de trastorno mental en un centro de salud mental [Prospective analysis of the nondiagnosed cases of mental illness in an 
outpatient setting] (Doctoral dissertation). Universidad Autónoma de Madrid, Madrid. Goldberg, D.P., \& Hillier, V.F. (1979). A scaled version of the General Health Questionnaire. Cambridge Journals: Psychological Medicine, 9(1), 139-45. https:/ /doi.org/10.1017/S0033291700021644

Hayes, S. C., Strosahl, K. D., \& Wilson, K. G. (1999; 2011). Acceptance and Commitment Therapy. Nueva York, NY: The Guildford Press.

Heisel, M. J., \& Flett, G. L. (2004). Purpose in life, satisfaction with life, and suicide ideation in a clinical sample. Journal of Psychopathology and Behavioral Assessment, 26(2), 127- 135. https://doi.org/10.1023/B: JOBA.0000013660.22413.e0

Hill, P. L., Edmonds, G. W., \& Hampson, S. E. (2017). A purposeful lifestyle is a healthful lifestyle: Linking sense of purpose to self-rated health through multiple health behaviors. Journal of Health Psychology. Online first. https://doi.org/10.1177/13591 05317708251

Hill, P. L., \& Turiano, N. A. (2014). Purpose in life as a predictor of mortality across adulthood. Psychological Science, 25(7), 1482-1486. https://doi.org/10.1177/095679 7614531799

Hill, P. L., Turiano, N. A., Mroczek, D. K., \& Burrow, A. L. (2016). The value of a purposeful life: Sense of purpose predicts greater income and net worth. Journal of Research in Personality, 65, 38-42. https://do i.org/10.1016/j.jrp.2016.07.003

Hill, P. L., Turiano, N. A., Spiro, A., \& Mroczek, D. K. (2015). Understanding interindividual variability in purpose: Longitudinal findings from the VA Normative Aging Study. Psychology and Aging, 30(3), 529-533. https:// doi.org/10.1037/pag0000020

Hooker, S. A., Masters, K. S. (2016). Purpose in life is associated with physical activity measured by accelerometer. Journal of Health Psychology, 21(6), 962-971. https:// doi.org/10.1177/1359105314542822
Irving, J., Davis, S., \& Collier, A. (2017). Aging with purpose: Systematic search and review of literature pertaining to older adults and purpose. The International Journal of Aging and Human Development, 85(4), 403-437. h ttps://doi.org/10.1177/0091415017702908

Kashdan, T.B., \& McKnight. P. E. (2013). Commitment to a purpose in life: An antidote to the suffering by individuals with social anxiety disorder. Emotion, 13(6), 1150-1159. https://doi.org/10.1037/a00332 78

Kim, E. S., Hershner, S. D., \& Strecher, V. J. (2015). Purpose in life and incidence of sleep disturbances. Journal of Behavioral Medicine, 38(3), 590-597. https://doi.org/10 $.1007 / \mathrm{s} 10865-015-9635-4$

Kim, E. S., Kawachi, I., Chen, Y., \& Kubzansky, L. D. (2017). Association between purpose in life and objective measures of physical function in older adults. JAMA Psychiatry, 74(10), 1039-1045. https://doi.org/10.1001 /jamapsychiatry.2017.2145

Kim, E. S., Strecher, V. J., \& Ryff, C. D. (2014). Purpose in life and use of preventive health care services. Proceedings of the National Academy of Sciences, 111(46), 16331-16336. https://doi.org/10.1073/pnas .1414826111

Kim, E. S., Sun, J. K., Park, N., Kubzansky, L. D., \& Peterson, C. (2013). Purpose in life and reduced risk of myocardial infarction among older US adults with coronary heart disease: A two-year follow-up. Journal of Behavioral Medicine, 36(2), 124-133. https: //doi.org/10.1007/s10865-012-9406-4

Langer, E. J., \& Rodin, J. (1976). The effects of choice and enhanced personal responsibility for the aged. A field experiment in an institutional setting. Journal of Personality and Social Psychology, 34(2), 191-198. https://doi.org/10.1037/00 22-3514.34.2.191

Lobo, A., Ezquerra, J., Gómez-Burgada, F., Sala, J. M., Seva-Díaz, A. (1979). El miniexamen cognoscitivo. Un test sencillo, práctico, para detectar alteraciones intelectuales en pacientes médicos [Cognitive miniexam. A 
practical and easy test to detect intelectual alterations in medical patients]. Actas Luso Españolas de Neurología Psiquiatrica y Ciencias Afines, 7(3), 189-202. Retrieved from https://www.researchgate.net/profile/ Antonio_Lobo6/publication/284696329_E 1_mini-examen_cognoscitivo_Un_test_sen cillo_y_prctico_para_detectar_alteracione s_intelectuales_en_pacientes_mdicos/links /565d84f008ae-1ef92982aa51/El-mini-exa men-cognoscitivo-Un-test-sencillo-y-prcti co-para-detectar-alteraciones-intelectuales -en-pacientes-mdicos.pdf

Lobo, A., Pérez-Echeverría, M. J., \& Artal, J. (1986) Validity of the scaled version of the General Health Questionnaire (GHQ-28) in a Spanish population. Psychological Medicine, 16(1), 135-140. https://doi.org/10 $.1017 /$ S0033291700002579

Luciano, C., Molina, F., Gutierrez-Martinez, O., Barnes-Holmes, D., Valdivia-Salas, S., Cabello, F., .... Wilson, K. G. (2010). The impact of acceptance-based versus avoidance-based protocols on discomfort. Behavior Modification, 34(2), 94-119. https: //doi.org/10.1177/0145445509357234

Lundman, B., Aléx, L., Jonsén, E., Norberg, A., Nygren, B., Fischer, R. S., \& Strandberg, G. (2010). Inner strenght. A theoretical analysis of salutogenic concepts. International Journal of Nursing Studies, 47(2), 251-260. https://doi.org/10.1016/j.ij nurstu.2009.05.020

Marco, J. H., García-Alandete J., Pérez S., \& Botella C. (2014). El sentido de la vida como variable mediadora entre la depresión y la desesperanza en pacientes con trastorno límite de la personalidad [Meaning in life as mediator between depression and hopelessness among borderline personality disorder patients]. Behavioral Psychology, 22(2), 291-303. Retrieved from http://repositori.uji.es/xmlui/bitstrea $\mathrm{m} /$ handle/10234/120322/64428.pdf?seque nce $=1$ \&isAllowed $=y$

Muthén, L. K. \& Muthén, B. O. (1998; 2010). Mplus User's Guide. Sixth Edition. Los Angeles,
CA: Muthén \& Muthén. Retrieved from https://www.statmodel.com/downloa d/usersguide/Mplus\%20Users\%20Guide\% 20v6.pdf

Noblejas de la Flor, M. A. (2000). Fiabilidad de los tests PIL y Logo-test [Reliability of the PIL and Logo-test]. NOUS: Boletín de Logoterapia y Análisis Existencial, 4, 81-90.

Páez-Blarrina, M., Luciano, C., GutiérrezMartínez, O., Valdivia-Salas, S., Ortega, J., \& Rodríguez-Valverde, M. (2008). The role of values with personal examples in altering the functions of pain: Comparison between acceptance-based and cognitivecontrol-based protocols. Behaviour Research and Therapy, 46(1), 84-97. https://doi.org/1 $0.1016 / j$.brat.2007.10.008

Rodin, J., \& Langer, E. J. (1977). Long-Term effects of a control-relevant intervention with the institutionalized aged. Journal of Personality and Social Psychology, 35(12), 897-902. https://doi.org/10.1037/0022-351 4.35.12.897

Ryff, C. D., \& Keyes, C. L. M. (1995). The structure of psychological well-being revisited. Journal of Personality and Social Psychology, 69(4), 719-727. https://doi.org/ 10.1037/0022-3514.69.4.719

Schaefer, S. M., Morozink-Boylan, J., VanReekum, C. M., Lapate, R. C., Norris, C. J., Ryff, C D., \& Davison, R. J. (2013). Purpose in life predicts better emotional recovery from negative stimuli. PLoS ONE, 8(11), e80329. https://doi.org/10.1371/journal.po ne.0080329

Schulenberg, S. E., Schnetzer, L. W., \& Buchanan, E. M. (2011). The purpose in life test-short form: Development and psychometric support. Journal of Happiness Studies, 12(5), 861-876. https://doi.org/10.1 007/s10902-010-9231-9

Sherman, A. C., \& Simonton, S. (2012). Effects of personal meaning among patients in primary and specialized care: Associations with psychological and physical outcomes. Psychology and Health, 27(4), 475-490. http s://doi.org/10.1080/08870446.2011.592983 
Sterling, M. (2011). General health questionnaire-28 (GHQ-28). Journal of Physiotherapy, 57(4), 259. https://doi.org/10 $.1016 / \mathrm{S} 1836-9553(11) 70060-1$

Strack, K. M., \& Schulenberg, S. E. (2009). Understanding empowerment, meaning, and perceived coercion in individuals with serious mental illness. Journal of Clinical Psychology, 65(10), 1137-1148. https:// doi.org/10.1002/jclp.20607

Valdivia-Salas, S., Blanchard, K.S., Lombas, A.S., \& Wulfert, E. (2014). Treatmentseeking precipitators in problem gambling: Analysis of data from a gambling helpline. Psychology of Addictive Behaviors, 28(1), 300-306. https://doi.org/10.1037/a0035413

Valdivia-Salas, S., Dougher, M., \& Luciano, C. (2013). Derived relations and generalized alteration of preferences. Learning and Behavior, 41(2), 205-217. http://dx.doi.org/ 10.3758/s13420-012-0098-y

Veenhoven, R. (1984). Conditions of Happiness. Holland, Dordrecht: Academic Publishers. https://doi.org/10.1007/978-94009-6432-7

Weich, S., Twigg, L., Holt, G., Lewis, G., \& Jones, K. (2003). Contextual risk factors for the common mental disorders in Britain: A multilevel investigation of the effects of place. Journal of Epidemiology $\mathbb{E}$ Community Health, 57, 616-621. http://dx.doi.org/10.1 136/jech.57.8.616

Wiesmann, U., \& Hannich, H. J. (2013). The contribution of resistance resources and sense of coherence to life satisfaction in older age. Journal of Happiness Studies, 14(3), 911-928. https://doi.org/10.1007/s10 902-012-9361-3

Wilson, K. G., \& Murrell, A. R. (2004). Values work in Acceptance and Commitment Therapy. In S. C. Hayes, V. Follete \& M. Linehan (Eds.), Mindfulness and acceptance: Expanding the cognitive-behavioral tradition (pp. 120-151). New York, NY: Guilford.

Windsor, T. D., Curtis, R. G., \& Luszcz, M. A. (2015). Sense of purpose as a psychological resource for aging well. Developmental
Psychology, 51(7), 975-986. https://doi.org/ $10.1037 / \mathrm{dev} 0000023$

\section{Notes}

* Research article. This research was partially funded with grant \#2013/B005 from Fundación Universitaria Antonio Gargallo and Fundación Ibercaja; and was conducted in partial fulfillment of the first author's Bachelor degree. 